\title{
Lemongrass essential oil and citral inhibit Src/Stat3 activity and suppress the proliferation/survival of small-cell lung cancer cells, alone or in combination with chemotherapeutic agents
}

\author{
TAKAYUKI MARUOKA ${ }^{1}$, AKIRA KITANAKA ${ }^{2}$, YOSHITSUGU KUBOTA $^{3}$, GENJI YAMAOKA ${ }^{4}$, \\ TOMOHIRO KAMEDA ${ }^{1}$, OSAMU IMATAKI ${ }^{1}$, HIROAKI DOBASHI ${ }^{1}$, SHUJI BANDOH ${ }^{1}$, \\ NORIMITSU KADOWAKI ${ }^{1}$ and TERUKAZU TANAKA ${ }^{1}$
}

\begin{abstract}
${ }^{1}$ Department of Internal Medicine, Division of Hematology, Rheumatology and Respiratory Medicine, Faculty of Medicine, Kagawa University, Miki, Kagawa 761-0793; ${ }^{2}$ Department of Laboratory Medicine, Kawasaki Medical School, Kurashiki, Okayama 701-0192; Departments of ${ }^{3}$ Community Medicine and ${ }^{4}$ Laboratory Medicine, Faculty of Medicine, Kagawa University, Miki, Kagawa 761-0793, Japan
\end{abstract}

Received October 11, 2017; Accepted February 22, 2018

DOI: $10.3892 /$ ijo. 2018.4314

\begin{abstract}
Small-cell lung cancer (SCLC) is intractable due to its high propensity for relapse. Novel agents are thus needed for SCLC treatment. Lemongrass essential oil (LG-EO) and its major constituent, citral, have been reported to inhibit the proliferation and survival of several types of cancer cells. However, the precise mechanisms through which LG-EO and citral exert their effects on SCLC cells have not been fully elucidated. SCLC cells express Src and have high levels of Src-tyrosine kinase (Src-TK) activity. In most SCLC cell lines, constitutive phosphorylation of Stat3(Y705), which is essential for its activation, has been detected. Src-TK can phosphorylate Stat3(Y705), and activated Stat3 promotes the expression of the anti-apoptotic factors Bcl-xL and Mcl-1. In the present study, LG-EO and citral prevented Src-TK from phosphorylating Stat3(Y705), resulting in decreased Bcl-xL and Mcl-1 expression, in turn suppressing the proliferation/survival of SCLC cells. To confirm these findings, the wild-type-src gene was transfected into the LU135 SCLC cell line (LU135-wt-src), in which Src and activated phospho-Stat3(Y705) were overexpressed. The suppression of cell proliferation and the induction of apoptosis by treatment with LG-EO or citral were significantly attenuated in the LU135-wt-src cells compared with the control LU135-mock cells. The signal transducer and activator of transcription 3 (Stat3) signaling pathway is also associated with intrinsic drug resistance. LU135-wt-src cells were
\end{abstract}

Correspondence to: Dr Terukazu Tanaka, Department of Internal Medicine, Division of Hematology, Rheumatology and Respiratory Medicine, Faculty of Medicine, Kagawa University, 1750-1 Ikenobe, Miki, Kita-gun, Kagawa 761-0793, Japan

E-mail: tanaka@med.kagawa-u.ac.jp

Key words: lemongrass essential oil, citral, small-cell lung cancer, Src, signal transducer and activator of transcription 3, chemotherapeutic agents, chemotherapy, combination therapy significantly resistant to conventional chemotherapeutic agents compared with LU135-mock cells. The combined effects of citral and each conventional chemotherapeutic agent on SCLC cells were also evaluated. The combination treatment exerted additive or more prominent effects on LU135-wt-src, LU165 and MN1112 cells, which are relatively chemoresistant SCLC cells. These findings suggest that either LG-EO or citral, alone or in combination with chemotherapeutic agents, may be a novel therapeutic option for SCLC patients.

\section{Introduction}

Lung cancer is the leading cause of cancer-related mortality and a major health concern worldwide. Small-cell lung cancer (SCLC) accounts for $\sim 12 \%$ of all lung cancer cases (1). The majority of SCLCs show a favorable response to initial chemotherapy, but have a high propensity for relapse and metastasis. Relapsed SCLC is generally refractory to chemotherapy and tends to progress rapidly. The prognosis of relapsed and refractory SCLC is very poor $(2,3)$. Therefore, novel agents are needed for the treatment of SCLC. Lemongrass (LG), Cymbopogon citratus, is a widely used herb in tropical countries. Tea and essential oil (EO) made from LG are popularly used for analgesic (4), anti-inflammatory (5,6), antibacterial (7) and antifungal $(8,9)$ purposes. A major constituent of LG-EO is citral (3,7-dimethyl-2,6-octadienal). LG-EO has been shown to inhibit the proliferation of human mouth epidermal carcinoma (KB) and murine leukemia (P388) cell lines (10). Citral was also reported to inhibit the growth of spontaneous tumors in mice (11) and to induce cell cycle arrest and apoptosis in tumor cell lines $(12,13)$. However, the precise mechanisms underlying these tumor-inhibiting effects on SCLC cells have not been fully elucidated.

In several types of cancer, including lung cancer, the transcription factor signal transducer and activator of transcription 3 (Stat3) is constitutively activated, and aberrant signaling via Stat3 is implicated in malignant transformation (14), and is associated with intrinsic resistance to chemotherapy $(15,16)$. 
Stat 3 is also expressed in primary SCLC tumor tissues as well as SCLC cell lines, and is strongly phosphorylated on tyrosine 705 (Y705) (17), which is essential for its activation.

Src expression was detected in SCLC cell lines (18-20). In resected human SCLC tissue samples, Src was expressed in 17 of 19 SCLC tumor tissues (21) and was found in all 4 of 4 SCLC cases (19). Src is frequently overexpressed in lung cancers, including SCLC (22). Src-tyrosine kinase (Src-TK) activity was detected in SCLC cell lines (20), and its level in SCLC tissues was higher compared with that in normal lung tissues (18). Src-TK can phosphorylate Stat3(Y705) independently of cytokine or growth factor receptor activation (23). The durable activation of Src-TK in tumor cells causes a constitutive activation of Stat $3(14,24)$. Activated Stat 3 promotes the expression of downstream target genes, such as the anti-apoptotic factors Bcl-xL and Mcl-1 $(25,26)$.

In the present study, we observed that LG-EO and citral both inhibited the phosphorylation of Src(Y416), which is essential for its activation, resulting in reduction of Stat3(Y705) phosphorylation, followed by disruption of cell growth and survival signal transduction pathways mediated by Stat 3 that upregulate the expression of Bcl-xL and Mcl-1. Therefore, both LG-EO and citral were shown to suppress the proliferation/survival of all of the SCLC cell lines in a similar dose-dependent manner.

Our experiments also revealed that wild-type-src (wt-src)-transfected and Src-overexpressing SCLC cells were significantly more resistant to LG-EO and citral, as well as to conventional chemotherapeutic agents, compared with control mock-transfected cells; however, the combination of citral and anticancer drugs enhanced the cytotoxic efficacy of these drugs on SCLC cells, including Src-overexpressing wt-src-transfectants. These findings suggest that either LG-EO or citral, alone or in combination with chemotherapeutic agents, may be a novel therapeutic option for patients with SCLC.

\section{Materials and methods}

Reagents and chemicals. LG-EO (lot no. 79), which contains citral at a concentration of $74.2 \%(\mathrm{v} / \mathrm{v})(4.31 \mathrm{M})$, was purchased from Seikatsu-no-ki (Tokyo, Japan). Citral was obtained from Nacalai Tesque (Kyoto, Japan). LG-EO and citral were dissolved in dimethyl sulfoxide (DMSO; Wako Pure Chemical Industries, Ltd., Osaka, Japan) at a concentration of $1 \%(\mathrm{v} / \mathrm{v})$ before use. PP2 and PP3 dissolved in DMSO, the protease inhibitor cocktail set 1 and G418 were purchased from Calbiochem (San Diego, CA, USA). WST-1 was obtained from Roche Diagnostics (Mannheim, Germany). Cisplatin (CDDP) from Wako Pure Chemical Industries, Ltd. and amrubicin (AMR) from Nippon Kayaku (Tokyo, Japan) were dissolved in $0.9 \%$ $\mathrm{NaCl}$ solution and distilled water, respectively, and stored at $-30^{\circ} \mathrm{C}$. Etoposide (VP-16) obtained from Wako Pure Chemical Industries, Ltd. and an active metabolite of irinotecan, 7-ethyl-10-hydroxycamptothecin (SN38), purchased from Tokyo Chemical Industry (Tokyo, Japan) were dissolved in DMSO and stored at $-30^{\circ} \mathrm{C}$. All other reagents and chemicals were purchased from commercial sources.

Antibodies. Anti-Src ( $\alpha \mathrm{Src})$ monoclonal antibody (mAb) was obtained from Calbiochem. $\alpha \operatorname{Src}$ and $\alpha \operatorname{Stat} 3$ polyclonal antibodies were purchased from Santa Cruz Biotechnology (Santa Cruz, CA, USA). Anti-phospho-Src(Y416) (ap-Src) $\mathrm{mAb}$ was purchased from Upstate Biotechnology (Lake Placid, NY, USA). $\alpha$ p-Stat3(Y705), $\alpha$ p-Akt(S473) and $\alpha$ Akt mAbs, and $\alpha$ Bcl-xL, $\alpha$ Mcl-1 and $\alpha$ GAPDH antibodies were purchased from Cell Signaling Technology, Inc. (Danvers, MA, USA). Horseradish peroxidase-conjugated anti-mouse IgG and anti-rabbit IgG antibodies were purchased from GE Healthcare UK (Buckinghamshire, UK).

Cells. The human SCLC cell lines LU134AM, LU135 and LU165 were obtained from the Japanese Cancer Research Resources Bank (Tokyo, Japan), and the MN1112 SCLC cell line was established in our laboratory (27). All cell lines were cultured in RPMI-1640 growth medium (Wako Pure Chemical Industries, Ltd.) supplemented with 5\% heat-inactivated fetal calf serum (FCS) and antibiotics (100 U/ml penicillin $\mathrm{G}$ and $100 \mu \mathrm{g} / \mathrm{ml}$ streptomycin) (Sigma-Aldrich; Merck KGaA, St. Louis, MO, USA).

Vectors and their transfection into the LU135 SCLC cell line. A eukaryotic expression vector containing murine wild-type$s r c$ (wt-src) cDNA in pUSE (pUSE-wt-src) and an empty vector pUSE (Upstate Biotechnology) were electroporated into LU135 cells as previously described (28). Briefly, pUSE-wt-src or empty pUSE $(25 \mu \mathrm{g})$ was electroporated into $5 \times 10^{6}$ LU135 cells using a gene pulser apparatus (Bio-Rad Laboratories, Richmond, CA, USA) set at $960 \mu \mathrm{F}$ and $290 \mathrm{~V}$. Transfected cells were cultured for $24 \mathrm{~h}$ in growth medium containing $10 \%$ FCS, and selected after a 3-week culture in the presence of $300 \mu \mathrm{g} / \mathrm{ml} \mathrm{G} 418$. Selected clones of pUSE- or pUSE-wt-srctransfected LU135 cells (LU135-mock or LU135-wt-src cells, respectively) were expanded and screened for the expression of Src protein by immunoprecipitation and western blotting.

Cell proliferation/survival assay. Cell proliferation/survival were determined using the WST-1 assay, according to the manufacturer's instructions. The SCLC cells were plated in flat-bottomed 96-well plates at a density of $5 \times 10^{4}$ cells/well (LU134AM, LU135, LU165, LU135-mock and LU135-wt-src) or $3 \times 10^{4}$ cells/well (MN1112). Various concentrations of LG-EO or citral were added to the cells and incubated at $37^{\circ} \mathrm{C}$ in a $5 \% \mathrm{CO}_{2}$ humidified atmosphere for $16 \mathrm{~h}$.

For the determination of the concentration producing $50 \%$ inhibition of cell growth $\left(\mathrm{IC}_{50}\right)$ in each SCLC cell line, each chemotherapeutic agent (CDDP, VP-16, AMR or SN38) at various concentrations was added to the wells containing $3 \times 10^{4}$ or $5 \times 10^{4}$ cells/well as mentioned above, and incubated under the same conditions for $72 \mathrm{~h}$, followed by the addition of $10 \mu \mathrm{l}$ WST-1 to each well and incubation for an additional $3 \mathrm{~h}$. The absorbance at $490 \mathrm{~nm}$ was measured using a microplate reader (model 680; Bio-Rad Laboratories).

Analysis of proteins in SCLC cells treated with LG-EO or citral. The SCLC cells $\left(1 \times 10^{7}\right.$ cells) were treated at $37^{\circ} \mathrm{C}$ for $2 \mathrm{~h}$ (for Src analysis) or $3 \mathrm{~h}$ (for Stat3, Bcl-xL, Mcl-1 and Akt analyses) with the growth medium containing LG-EO at a concentration of 0.0035 or $0.01 \%(\mathrm{v} / \mathrm{v})$ (concentration of citral, $151 \mu \mathrm{M}$ or $431 \mu \mathrm{M}$, respectively), citral at a concentration of $150 \mu \mathrm{M}$ or $400 \mu \mathrm{M}$, or $1 \%$ (v/v) DMSO as control. In 
addition, LU135-wt-src and LU135-mock cells were treated with the growth medium containing $100 \mu \mathrm{M}$ PP2 or $100 \mu \mathrm{M}$ $\mathrm{PP} 3$ as control at $37^{\circ} \mathrm{C}$ for $2 \mathrm{~h}$ (for Src analysis) or $3 \mathrm{~h}$ (for Stat 3 analysis). The cells were lysed in lysis buffer $[50 \mathrm{mM}$ Tris-HCl, pH 7.5, $150 \mathrm{mM} \mathrm{NaCl}, 1 \%$ (v/v) Triton X-100, $1 \mathrm{mM}$ EDTA-2Na, $2 \mathrm{mM} \mathrm{Na}_{3} \mathrm{VO}_{4}, 2 \mathrm{mM} \mathrm{NaF}$ and $1 \%(\mathrm{v} / \mathrm{v})$ protease inhibitor cocktail set 1]. For the immunoprecipitation of $\mathrm{Src}$ and Stat 3 , the $\alpha \operatorname{Src} \mathrm{mAb}$ and $\alpha \mathrm{Stat} 3$ antibody, respectively, and Dynabeads protein G (Dynal, Oslo, Norway) were added to the lysates, and the immune complexes were washed with the lysis buffer using DynaMag-2 (Dynal) according to the manufacturer's instructions.

The immunoprecipitates and the total cell lysates [for the analyses of Bcl-xL, Mcl-1, Akt, p-Akt(S473) and GAPDH] were resuspended and dissolved in sample buffer $(195 \mathrm{mM}$ Tris-HCl, pH 6.8, 30\% glycerol, 15\% 2-mercaptoethanol, $9 \%$ SDS and $0.05 \%$ bromphenol blue), boiled for $3 \mathrm{~min}$, and separated by SDS-PAGE (10\%). The separated proteins were electrotransferred to PVDF membranes (Millipore, Bedford, MA, USA). The membranes were blocked in phosphatebuffered saline (PBS) with $0.1 \%$ Tween-20 (PBST) containing $3 \%$ bovine serum albumin at room temperature for $1 \mathrm{~h}$, and then incubated with the respective primary antibodies (1:1,000-1:3,000 diluted in PBST) at room temperature for $1 \mathrm{~h}$.

The membranes were then washed in PBST and incubated with horseradish peroxidase-conjugated secondary antibodies (1:10,000 diluted in PBST) at room temperature for $1 \mathrm{~h}$. After washing, the membranes were developed using the enhanced chemiluminescence prime western blotting detection reagent (GE Healthcare). The membranes were subsequently stripped by a stripping buffer (Jacksun Easy Biotech, Bronx, NY, USA) according to the manufacturer's instructions and re-probed with the relevant antibodies. All experiments were repeated independently at least three times.

Apoptosis assay. An apoptosis assay was performed using an Apo ssDNA kit (Cell Technology, Mountain View, CA, USA), an antibody-based assay to detect DNA damage in apoptotic cells, according to the manufacturer's instructions and as described previously (28). Briefly, the cells were fixed in the fixative at $-20^{\circ} \mathrm{C}$ for $24-48 \mathrm{~h}$, resuspended in the DNA denaturing buffer and heated at $80^{\circ} \mathrm{C}$ for $10 \mathrm{~min}$. After being heated and blocked in casein blocking buffer (Thermo Scientific, Rockford, IL, USA), the cells were stained by indirect immunofluorescence using an anti-single-stranded DNA (ssDNA) mouse monoclonal IgM antibody. After washing, the cells were analyzed with a NAVIOS flowcytometer (Beckman Coulter, Miami, FL, USA) equipped with FlowJo 8.8.2 software (FlowJo, Ashland, OR, USA). The experiments were repeated independently three times.

Analysis of the combination effects of citral and a chemotherapeutic agent on the proliferation/survival of SCLC cells. LU135-wt-src, LU165 and MN1112 cells were treated with the combination of citral and each chemotherapeutic agent at the concentration of $\mathrm{IC}_{50}$ or less, under the same conditions as described above for $72 \mathrm{~h}$. The proliferation/survival of each cell line was assessed by the WST-1 assay. At least three independent experiments with triplicate samples were performed in each investigation. The combination effects of citral and each indicated chemotherapeutic agent were analyzed by the Bliss Independence model $(29,30)$. The combination index (CI) was calculated as follows: $C I=E_{A}+E_{B}-E_{A} E_{B} / E_{A B}$, where $E_{A}$ represents the cell growth inhibition effect of citral administered at a dose of $\mathrm{IC}_{50}$ or less, $\mathrm{E}_{\mathrm{B}}$ is the cell growth inhibition effect of each indicated chemotherapeutic agent administered at a dose of $\mathrm{IC}_{50}$ or less, and $\mathrm{E}_{\mathrm{AB}}$ is the cell growth inhibition effect of the combination of citral and each chemotherapeutic agent at the same concentrations as described above.

Statistical analysis. Data were analyzed by Student's t-test; $\mathrm{P}<0.05$ was considered to indicate a statistically significant difference.

\section{Results}

LG-EO and citral dose-dependently suppress the proliferation/survival of the SCLC cell lines. The effects of LG-EO and citral on the proliferation/survival of the four SCLC cell lines were evaluated by the WST-1 assay. The cell lines were cultured for $16 \mathrm{~h}$ in the presence of LG-EO at various concentrations, or DMSO alone as a control. As shown in Fig. 1, LG-EO at the indicated concentrations suppressed the proliferation/survival of all four SCLC cell lines in a very similar dose-dependent manner. $\mathrm{The} \mathrm{IC}_{50}$ was highest in the MN1112 cell line, followed by the LU165, LU134AM and LU135 cell lines (Fig. 1, left panel).

We investigated whether the inhibitory effect of LG-EO on cell proliferation/survival is due to its major constituent, citral. The growth inhibition of the SCLC cell lines treated with citral at various concentrations was determined under the same conditions as those used for the LG-EO treatment. As shown in Fig. 1, citral at the indicated concentrations also suppressed the proliferation/survival of all four cell lines in a similar dose-dependent manner. The $\mathrm{IC}_{50}$ of citral was highest in the LU165 cells, followed by the MN1112, LU134AM and LU135 cells (Fig. 1, right panel). These findings revealed that the inhibitory effects of citral on the proliferation/survival of SCLC cell lines were similar to those of LG-EO, indicating that the activity of LG-EO against the SCLC cells was due mainly to the action of citral.

Effects of LG-EO and citral on the constitutive phosphorylation of Src(Y416) and Stat3(Y705) in the SCLC cell lines. Elevated Src protein levels and/or Src-TK activity have been reported in lung cancer (19), including $\operatorname{SCLC}(19,20)$. Blockade of Src-TK has been shown to decrease the proliferation/survival of SCLC cells (22). Based on the accumulated evidence, we investigated the effects of LG-EO and those of citral on the constitutive phosphorylation of $\operatorname{Src}(\mathrm{Y} 416)$ [p-Src(Y416)] in the four SCLC cell lines. p-Src(Y416) was detected in various amounts in all four cell lines, and it was reduced by treatment with LG-EO at concentrations of 0.0035 or $0.01 \%$ for $2 \mathrm{~h}$ compared with that in the control cells treated with vehicle DMSO alone (Fig. $2 \mathrm{~A}$ ). In the cells treated with citral at concentrations of 150 or $400 \mu \mathrm{M}$ for $2 \mathrm{~h}$, the reduction in the constitutive phosphorylation of $\operatorname{Src}(Y 416)$ was similar to that in the cells treated for $2 \mathrm{~h}$ with LG-EO at concentrations 0.0035 or $0.01 \%$, respectively. In MN1112 cells, however, the treatment with 150 or $400 \mu \mathrm{M}$ citral decreased the p-Src(Y416) 

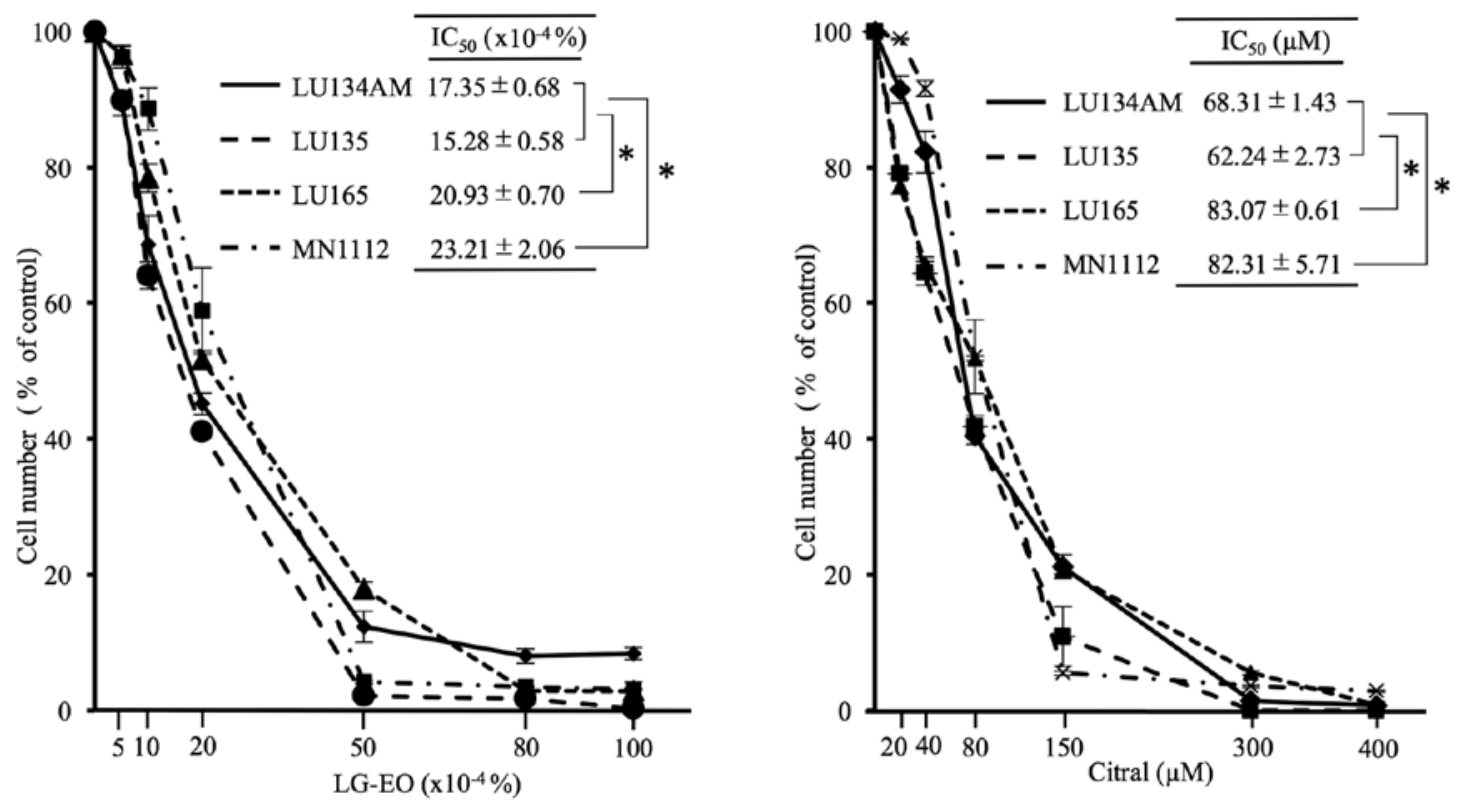

Figure 1. The proliferation and survival of four SCLC cell lines were dose-dependently suppressed by LG-EO and citral. The SCLC cell lines were cultured in the presence of LG-EO (left panel) or citral (right panel) at the indicated concentrations for $16 \mathrm{~h}$, and the proliferation and survival of the cells were evaluated by the WST-1 assay. The ratios of the cell number after treatment with LG-EO or citral at the indicated concentrations to the number of control cells after treatment with vehicle DMSO alone are shown. The $\mathrm{IC}_{50}$ values were determined by the WST-1 assay. The results are presented as the mean \pm standard deviation of three measurements. "Statistically significant at $\mathrm{P}<0.05$ by Student's t-test. SCLC, small-cell lung cancer; LG-EO, lemongrass essential oil; DMSO, dimethyl sulfoxide.

more prominently compared with 0.0035 or $0.01 \%$ LG-EO, respectively (Fig. 2A).

Phosphorylation of $\operatorname{Src}(Y 416)$ is crucial for Src-TK activation; therefore, its reduction diminishes Src-TK activity. Activated Src-TK phosphorylates Stat3(Y705) (31,32), resulting in the activation of Stat 3 as a transcription factor. Treatment for $3 \mathrm{~h}$ with LG-EO and treatment with citral under the same conditions as described above reduced the phosphorylation of Stat3(Y705) in all four SCLC cell lines, and the treatments at the respective higher concentrations suppressed the phosphorylation more prominently in the LU134AM and LU135 cell lines compared with the LU165 and MN1112 cell lines (Fig. 2B). The LU134AM and LU135 cell lines had lower $\mathrm{IC}_{50}$ values for each reagent compared with the other two cell lines (Fig. 1).

Effects of $L G-E O$ and citral on the expressions of Bcl-xL and Mcl-1. To study the effects of LG-EO and citral on the expression of the anti-apoptotic factors Bcl-xL and Mcl-1, which are dependent on Stat 3 activity $(25,26)$, each SCLC cell line was treated with LG-EO, citral, or vehicle DMSO alone for $3 \mathrm{~h}$. In all four SCLC cell lines examined, the expression of the anti-apoptotic factors was reduced by various degrees following treatment with LG-EO at concentrations of 0.0035 and $0.01 \%$ (LG-EO lanes, Fig. 2C) and treatment with citral at concentrations of 150 and $400 \mu \mathrm{M}$ (citral lanes, Fig. 2C) compared with that following treatment with DMSO alone (DMSO lanes, Fig. 2C).

In the LU134AM and MN1112 cell lines, the reduction in Bcl-xL expression were smaller compared with that in the other cell lines following treatment with LG-EO and citral at the respective higher concentrations (Fig. 2C, lower panel, top row). The Mcl-1 expression declined in all four SCLC cell lines following treatment under the same conditions as mentioned above (Fig. 2C, lower panel, middle row).

Effects of Src overexpression on the inhibition of the phosphorylation of Src(Y416) and Stat3(Y705) induced by LG-EO, citral or PP2. To confirm that the overexpression of Src would enhance the phosphorylation of Src(Y416) and Stat3(Y705), we transfected the wt-src-recombined or empty vector plasmid into LU135 cells and established LU135-wt-src or LU135-mock cells, respectively. We observed that Src was clearly overexpressed in three clones of LU135-wt-src (representatives out of seven) compared with LU135-mock cells (Fig. 3A). The levels of the phosphorylation of $\operatorname{Src}(\mathrm{Y} 416)$ and Stat3(Y705) in the LU135-wt-src cells were clearly higher compared with those in the control LU135-mock cells (DMSO lanes, Fig. 3B, upper and lower panels, top rows), and were correlated with the levels of Src expression.

We next examined the effects of Src overexpression on the inhibition of the phosphorylation of $\operatorname{Src}(\mathrm{Y} 416)$ and Stat3(Y705) in the transfectants by treatment with $0.01 \%$ LG-EO and $400 \mu \mathrm{M}$ citral. The treatments reduced the phosphorylation of both Src(Y416) and Stat3(Y705) in the LU135-wt-src as well as the LU135-mock cells, but the reduction of the phosphorylation in the former cells was less prominent compared with that in the latter cells (LG-EO and citral lanes, Fig. 3B upper and lower panels, top rows). These findings indicate that the overexpression of Src attenuates the inhibitory effects of LG-EO or citral on the activation of Src and Stat3.

Next, to examine whether the Src-TK activity was correlated with the phosphorylation of Src(Y416) and Stat3(Y705), the selective Src-TK inhibitor PP2 was used $(33,34)$. The two transfectants were treated with $100 \mu \mathrm{M}$ PP2 or $100 \mu \mathrm{M}$ PP3, an inactive analog of PP2. The phosphorylation of $\mathrm{Src}(\mathrm{Y} 416)$ 


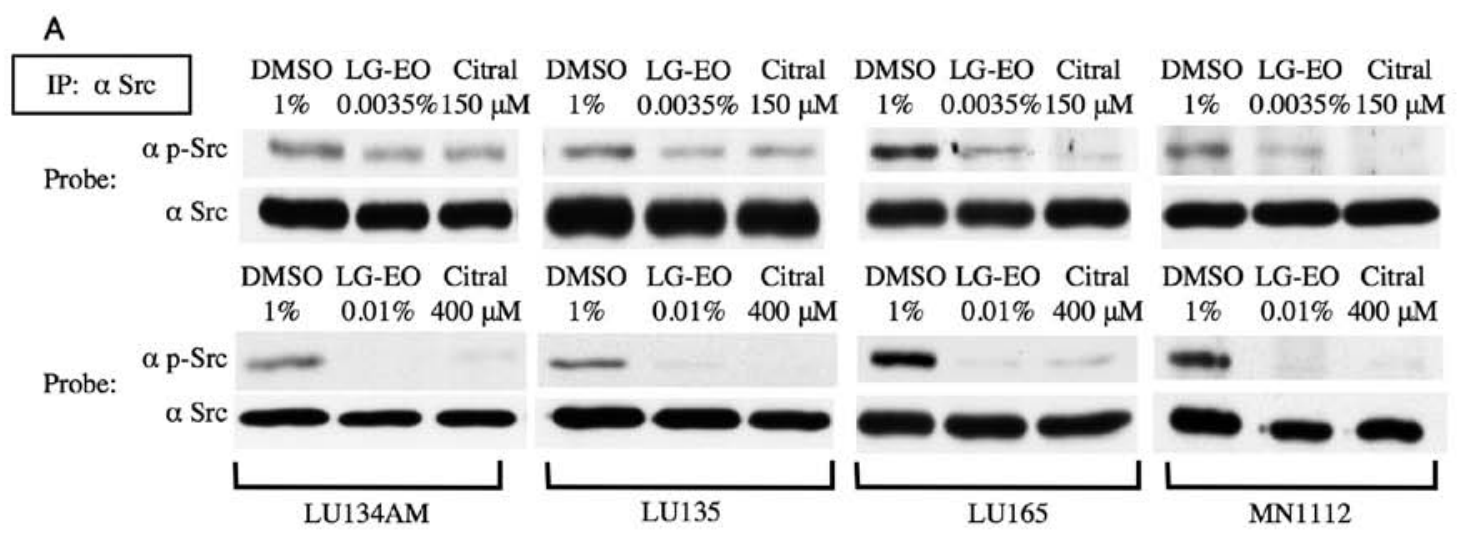

B

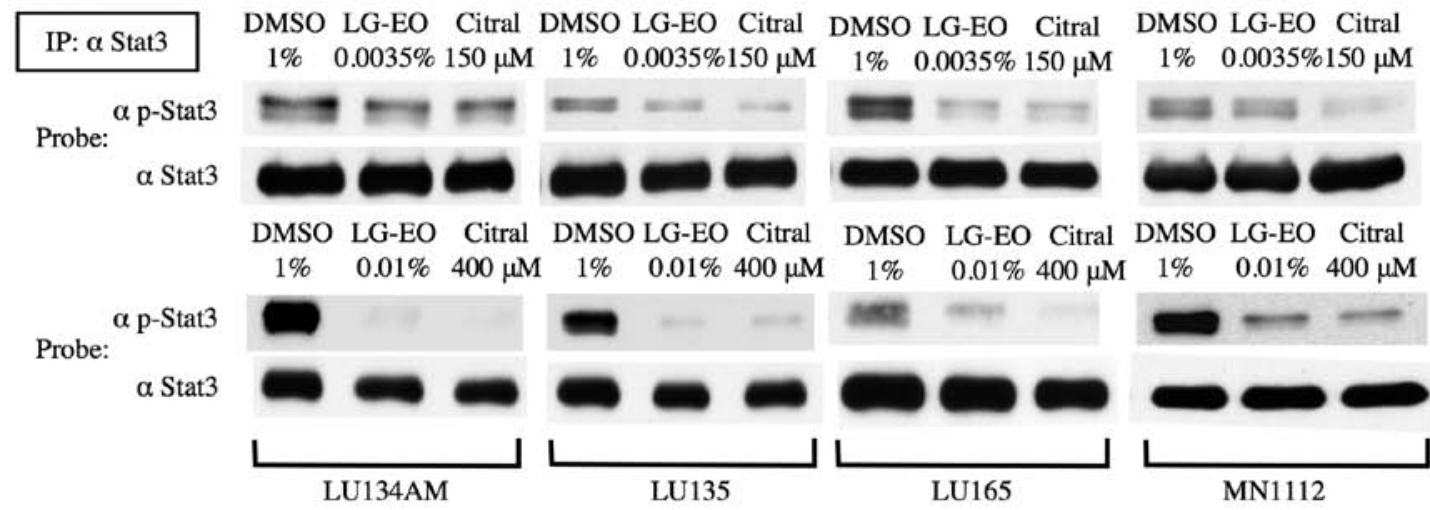

C

DMSO LG-EO Citral DMSO LG-EO Citral DMSO LG-EO Citral DMSO LG-EO Citral $\begin{array}{lllllllllllll}1 \% & 0.0035 \% & 150 \mu \mathrm{M} & 1 \% & 0.0035 \% & 150 \mu \mathrm{M} & 1 \% & 0.0035 \% & 150 \mu \mathrm{M} & 1 \% & 0.0035 \% & 150 \mu \mathrm{M}\end{array}$

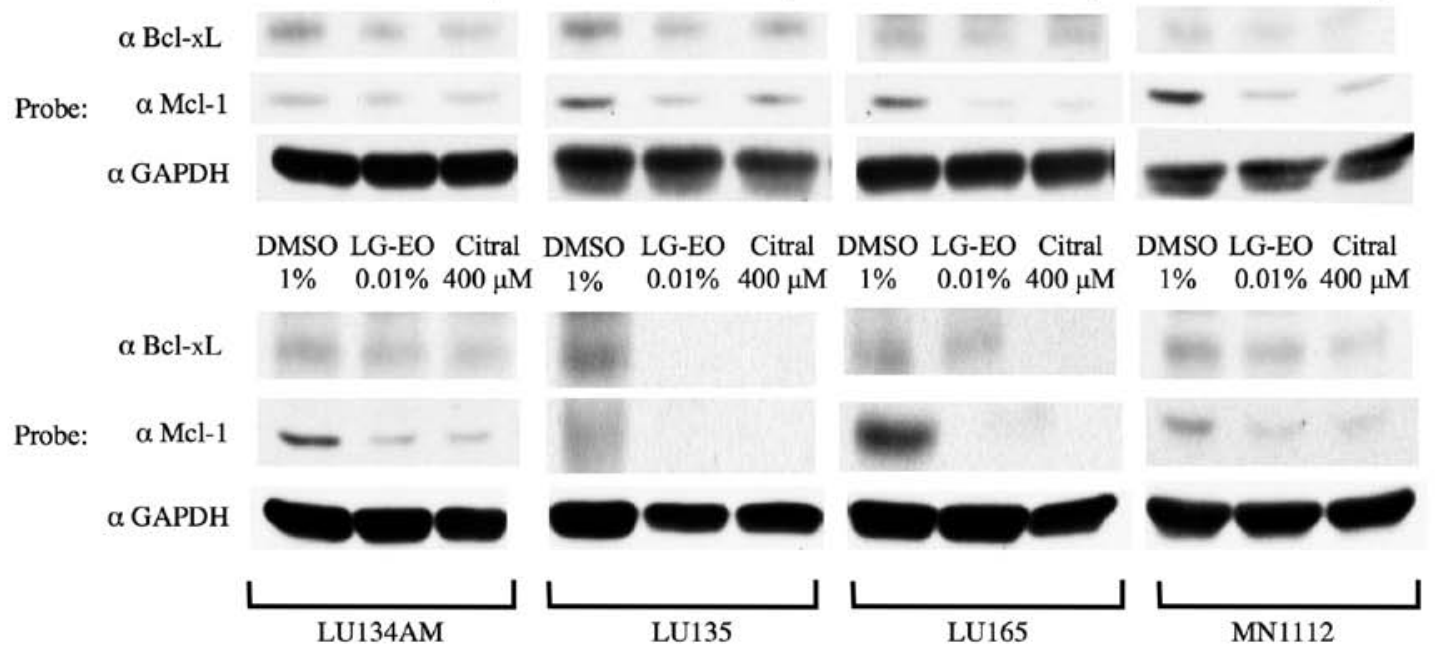

Figure 2. Effects of the treatment with LG-EO or citral on the constitutive phosphorylation of (A) Src(Y416) and (B) Stat3(Y705), and (C) the expressions of Bcl-xL and Mcl-1 in SCLC cell lines were examined by immunoprecipitation and/or western blotting, as described in Materials and methods. (A) The cell lines were treated with LG-EO $(0.0035$ or $0.01 \%)$, citral $(150$ or $400 \mu \mathrm{M})$ or vehicle DMSO $(1 \%)$ alone for $2 \mathrm{~h}$ to determine the effects on the reduction of the constitutive phosphorylation of Src(Y416). (B) The reduction of the constitutive phosphorylation of Stat3(Y705) was examined in the cell lines treated for $3 \mathrm{~h}$ with LG-EO, citral or DMSO at the same concentrations as mentioned above. (C) The reduction in the expressions of Bcl-xL and Mcl-1 in the SCLC cell lines treated under the same conditions as described for (B). After treatment, total cell lysates (5x10 5 cells of LU134AM, LU135 and LU165, and 3x10 ${ }^{5}$ cells of MN1112) were subjected to western blot analyses with $\alpha$ Bcl-xL, $\alpha$ Mcl-1 and $\alpha$ GAPDH antibodies as described in Materials and methods. Upper panels, treated with LG-EO or citral at concentrations of $0.0035 \%$ or $150 \mu \mathrm{M}$, respectively, and $1 \%$ DMSO alone. Lower panels, treated with LG-EO or citral at concentrations of $0.01 \%$ or $400 \mu \mathrm{M}$, respectively, and $1 \%$ DMSO alone. SCLC, small-cell lung cancer; LG-EO, lemongrass essential oil; DMSO, dimethyl sulfoxide; Stat3, signal transducer and activator of transcription 3; GAPDH, glyceraldehyde 3-phosphate dehydrogenase.

in both transfectants was almost completely inhibited by PP2 treatment, whereas PP3 exerted no effect on the phosphorylation of the two transfectants (PP3 and PP2 lanes, Fig. 3C, upper panel, top row). Although treatment with PP2 also reduced the phosphorylation of Stat3(Y705) (PP3 and PP2 lanes, Fig. 3C, lower panel, top row), the extent of the reduction was lesser 


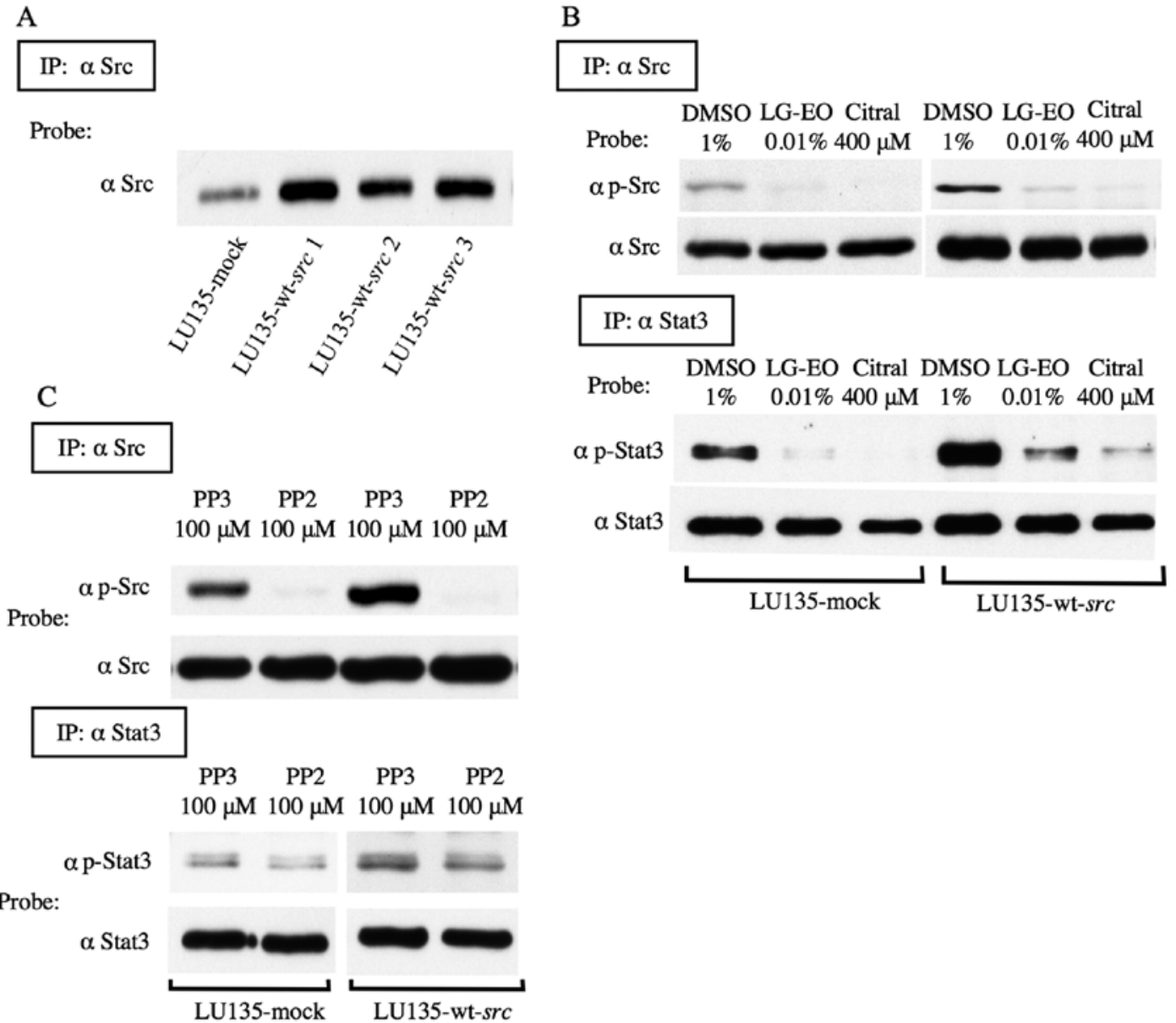

Figure 3. Level of Src expression and effects of the Src overexpression on the reductions of p-Src(Y416) and p-Stat3(Y705) in LU135-mock and LU135-wt-src cells treated with LG-EO, citral or PP2. Immunoprecipitation and western blotting were performed as described in Materials and methods. (A) The levels of Src expression in LU135-mock and 3 clones of LU135-wt-src determined by immunoprobing with $\alpha$ Src antibody. (B) The two transfectants were treated with LG-EO (0.01\%), citral $(400 \mu \mathrm{M})$ or DMSO (1\%) alone, as described for Fig. 2A and B for the determination of the effects on the reductions of p-Src(Y416) (upper panel, top row) and p-Stat3(Y705) (lower panel, top row), respectively. Determination of Src and Stat3 by re-probing with $\alpha$ Src antibody (upper panel, bottom row) and $\alpha$ Stat 3 antibody (lower panel, bottom row), respectively. (C) The two transfectants were treated with PP2 (100 $\mu \mathrm{M})$ or PP3 (100 $\mu \mathrm{M})$ for $2 \mathrm{~h}$ to determine the effects on the reductions of $\mathrm{p}-\mathrm{Src}(\mathrm{Y} 416)$ (upper panel, top row) and for $3 \mathrm{~h}$ to determine the effects on the reductions of p-Stat3(Y705) (lower panel, top row). The levels of Src and Stat3 were determined by re-probing with $\alpha$ Src antibody (upper panel, bottom row) and $\alpha$ Stat 3 antibody (lower panel, bottom row), respectively. LG-EO, lemongrass essential oil; DMSO, dimethyl sulfoxide; Stat3, signal transducer and activator of transcription 3.

compared with that of $\operatorname{Src}(\mathrm{Y} 416)$, and phosphorylated Stat3(Y705) was still detectable (PP3 and PP2 lanes, Fig. 3C, lower panel, top row).

Effects of LG-EO and citral on the proliferation/survival and apoptosis of LU135-wt-src cells. We examined whether Src overexpression reduces the cell growth inhibitory effect of LG-EO or citral. The LU135-wt-src and control LU135-mock cells were treated with each reagent at the indicated concentrations for $16 \mathrm{~h}$ and, as shown in Fig. 4A, the reduction in the number of LU135-wt-src cells was significantly less prominent compared with the reduction in the number of the control cells following treatment with LG-EO at concentrations of $0.0005-0.002 \%$ (corresponding to $21.6-86.2 \mu \mathrm{M}$ citral) (left panel) and following treatment with citral at concentrations of 20-80 $\mu \mathrm{M}$ (right panel). The $\mathrm{IC}_{50}$ of LU135-wt-src cells for LG-EO or citral was significantly higher compared with that of the control cells for each reagent (Fig. 4A, left and right panels).

To study the effect of Src overexpression on LG-EO- or citral-induced apoptosis, the two transfectants were treated with $0.01 \%$ LG-EO or $400 \mu \mathrm{M}$ citral for $3 \mathrm{~h}$. The apoptosis induced in these cells was evaluated by indirect immunofluorescence using an anti-ssDNA antibody followed by flow cytometric analysis, and compared with that in the cells treated with DMSO alone (Fig. 4B). The ratios of the mean fluorescence intensity (MFI) (LG-EO/DMSO MFI and citral/DMSO MFI) were decreased in the LU135-wt-src cells compared with the control LU135-mock cells: 3.88 vs. 2.40 (LG-EO/DMSO) and 5.15 vs. 3.32 (citral/DMSO), respectively (Fig. 4B left and right panels). These results indicate that $\mathrm{Src}$ overexpression followed by upregulation of Stat3(Y705) phosphorylation clearly attenuated the apoptosis induced by LG-EO or citral in the LU135-wt-src cells compared with the control cells.

Combined effects of citral and each of the four conventional chemotherapeutic agents on the proliferation/survival of SCLC cell lines. The results of several studies suggested that the upregulation of Stat 3 confers a drug-resistant phenotype $(16,23)$. Therefore, LU135-wt-src and control LU135-mock cells were treated with CDDP, VP-16, AMR, or SN38 at various concentrations for $72 \mathrm{~h}$. The results revealed that the LU135-wt-src cells were significantly more resistant 

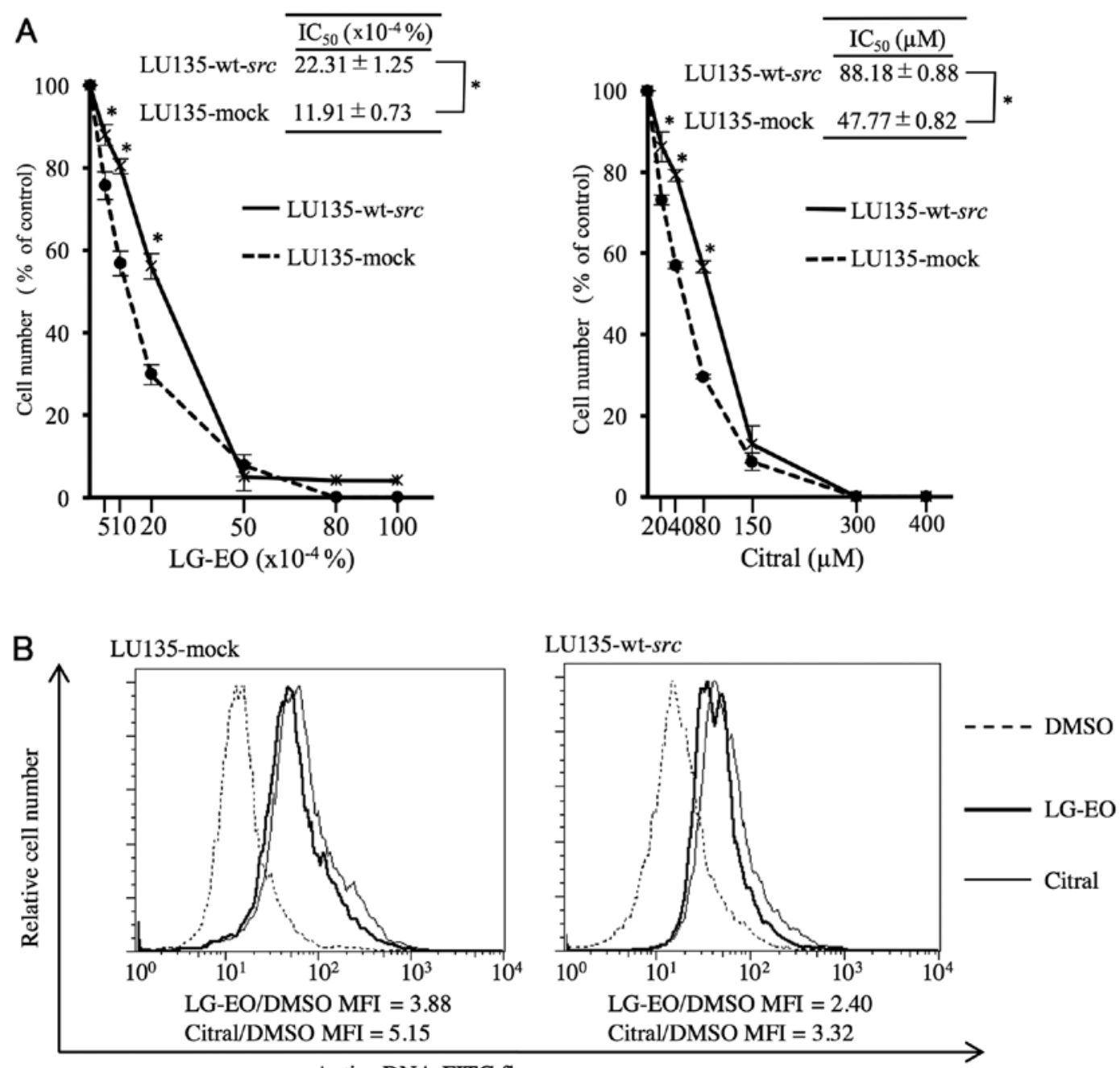

Anti-ssDNA-FITC fluorescence

Figure 4. Suppression of the proliferation/survival of LU135-wt-src and LU135-mock cells by LG-EO and citral. (A) The cells were cultured in the presence of LG-EO (left) or citral (right) at the indicated concentrations for $16 \mathrm{~h}$, and the proliferation/survival was evaluated by the WST-1 assay. The ratios of the number of cells after treatment with LG-EO or citral at the indicated concentrations to the number of control cells after treatment with vehicle DMSO alone are shown. The $\mathrm{IC}_{50}$ values were determined by the WST-1 assay. The results are presented as the mean \pm standard deviation of three measurements. "Statistically significant at $\mathrm{P}<0.05$ by Student's t-test. (B) Src overexpression attenuated the LG-EO- or citral-induced apoptosis in LU135-wt-src cells. The apoptosis induced in the LU135-mock (left panel) and LU135-wt-src (right panel) cells by treatment with $0.01 \%$ LG-EO or $400 \mu \mathrm{M}$ citral for $3 \mathrm{~h}$ was evaluated by indirect immunofluorescence using an anti-ssDNA mAb followed by flow cytometric analysis. The ratio of MFI of the LU135-wt-src cells treated with LG-EO or citral to that of the cells treated with $1 \%$ DMSO alone was compared with the ratio of MFI of the LU135-mock cells treated with LG-EO or citral to that of the cells treated with DMSO alone. The data shown are representative of three individual sets of experiments. LG-EO, lemongrass essential oil; DMSO, dimethyl sulfoxide; MFI, mean fluorescence intensity.

to CDDP at concentrations of $1-5 \mu \mathrm{M}$, to VP-16 and AMR at concentrations of $0.4-1.0 \mu \mathrm{M}$, and to $\mathrm{SN} 38$ at the concentrations of 5-40 nM compared with the control cells (Fig. 5A). The $\mathrm{IC}_{50}$ value of LU135-wt-src for each chemotherapeutic agent was significantly higher compared with that of the control LU135-mock cells (Fig. 5A).

To evaluate the combined effect of citral and each of the chemotherapeutic agents, the four SCLC cell lines were treated with each agent at various concentrations, and the $\mathrm{IC}_{50}$ value of each cell line for each chemotherapeutic agent was determined by WST-1 assay. As shown in Fig. 5B, the $\mathrm{IC}_{50}$ values of the LU165 and MN1112 cell lines for each of the chemotherapeutic agents were significantly higher compared with those of the LU134AM and LU135 cell lines. Based on these data, we determined whether the combination of citral and each chemotherapeutic agent would efficiently inhibit the proliferation/survival of the relatively chemoresistant
LU135-wt-src, LU165 and MN1112 cells. These cells were treated with citral or each chemotherapeutic agent alone, or with the combination of citral and each agent for $72 \mathrm{~h}$. In this experiment, each of the chemotherapeutic agents and citral were used at the indicated concentrations, which were the $\mathrm{IC}_{50}$ or less for each cell line. After $72 \mathrm{~h}$ of treatment, the proliferation/survival of each cell line was assessed by the WST-1 assay. As shown in Fig. 5C, the combination index (CI) of each of the relatively chemoresistant cell lines treated with the combination of citral and each chemotherapeutic agent was $<1$, but the CI value of the MN1112 cells treated with the combination of citral and CDDP or SN38 was very close to 1 (0.9900 or 0.9634 , respectively).

These results suggest that the combination of citral and each chemotherapeutic agent exerts an additive or higher cell growth inhibitory effect on the relatively chemoresistant LU165 and MN1112 SCLC cells, as well as on the Src-overexpressing 
A

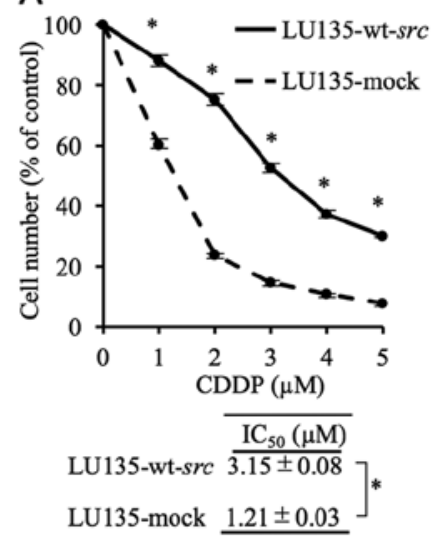

B

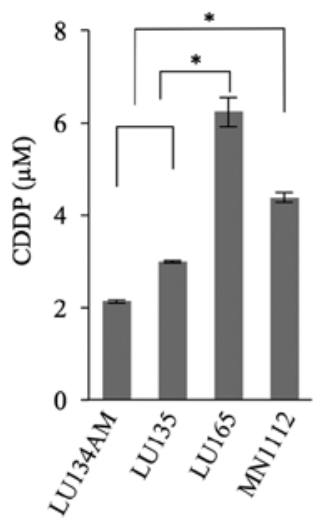

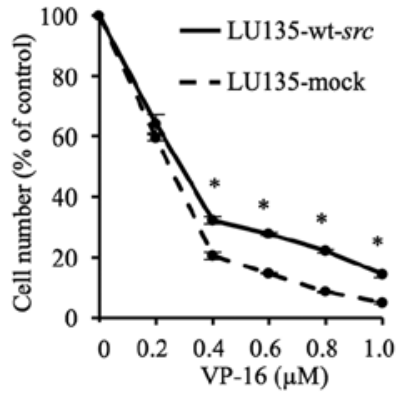

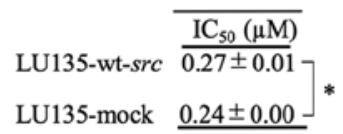

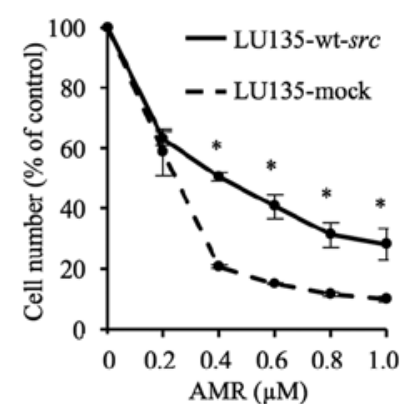

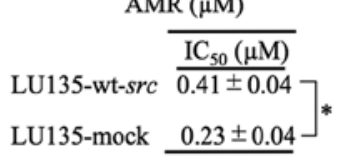

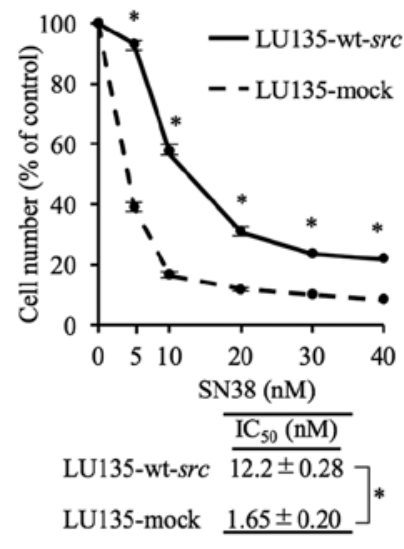

c

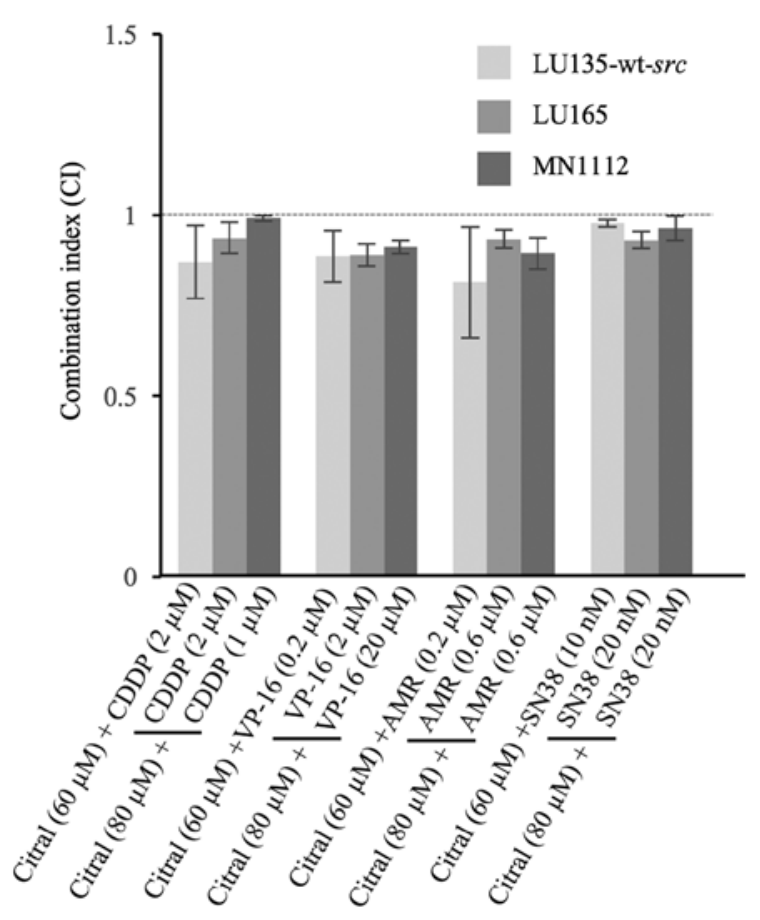

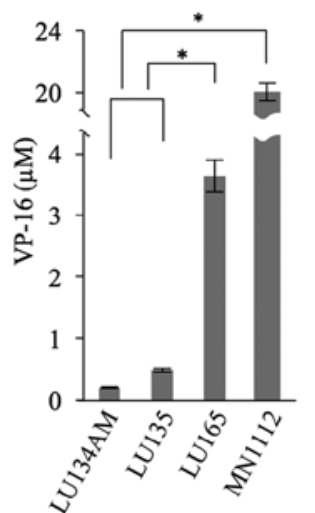

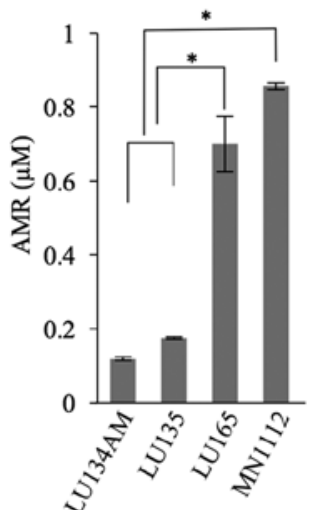

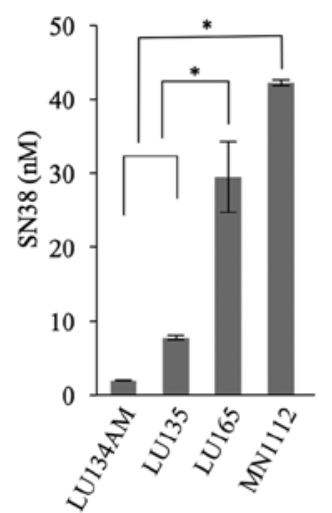

Figure 5. Combination effects of citral and each of the four chemotherapeutic agents on the proliferation/survival of relatively chemoresistant SCLC cells. (A) The LU135-wt-src and control LU135-mock cells were treated with CDDP, VP-16, AMR or SN38 at the indicated concentrations for $72 \mathrm{~h}$, and their proliferation/survival was evaluated by the WST-1 assay. The ratios of the number of cells after treatment with each chemotherapeutic agent at the indicated concentrations to the number of untreated control cells are shown. The $\mathrm{IC}_{50}$ values were determined by the WST- 1 assay. The results are presented as the mean \pm standard deviation of three measurements. "Statistically significant at $\mathrm{P}<0.05$ by Student's t-test. (B) The $\mathrm{IC}_{50}$ values of the four SCLC cell lines for each chemotherapeutic agent were determined by the WST-1 assay. The results are presented as the mean \pm standard deviation of three measurements. "Statistically significant at $\mathrm{P}<0.05$ by Student's t-test. (C) The relatively chemoresistant LU135-wt-src, LU165 and MN1112 cells were treated with a combination of citral and each chemotherapeutic agent for $72 \mathrm{~h}$. The combination treatment effects on the cell proliferation/survival were determined by the WST-1 assay. Citral and each of the agents were used at the indicated concentrations, which were the $\mathrm{IC}_{50}$ or less for each cell line. The combination effects were evaluated with a Bliss Independence analysis. The combination index (CI) value of each cell line was calculated as described in Materials and methods. A value of $\mathrm{CI}<1$ indicates synergism, a value of $\mathrm{CI}=1$ indicates an additive effect, and a value of $\mathrm{CI}>1$ indicates antagonism. The data represent the mean \pm standard deviation of three independent experiments. SCLC, small-cell lung cancer; CDDP, cisplatin; VP-16, etoposide; AMR, amrubicin; SN38, 7-ethyl-10-hydroxycamptothecin. 
LU135-wt-src cells, which exhibit upregulated Stat3(Y705) phosphorylation and chemoresistance to anticancer drugs compared with the control LU135-mock cells.

\section{Discussion}

The results of the present study demonstrated that LG-EO and its major constituent, citral, inhibited the constitutive activation of Src-TK, resulting in suppression of Stat 3 activity, which reduced the expression of the anti-apoptotic factors Bcl-xL and Mcl-1, and consequently induced apoptosis, followed by the decline of proliferation/survival in all four of the SCLC cell lines examined. The reduction of Mcl-1 expression was found to be more closely correlated with the suppression of proliferation/survival in the SCLC cell lines compared with the reduction of $\mathrm{Bcl}-\mathrm{xL}$ expression. We also observed that the overexpression of Src significantly enhanced the resistance to LG-EO, citral and the conventional chemotherapeutic agents CDDP, VP-16, AMR and SN38 in LU135-wt-src cells.

Stat 3 is constitutively activated in several cancers, and aberrant signaling via Stat 3 has been implicated in malignant transformation, particularly that induced by Src-TK $(14,32)$. Stat 3 is also expressed and activated in both SCLC tumor tissues and SCLC cell lines (17). It was reported that the constitutive phosphorylation of Stat3(Y705) was detected in 100\% (10/10) of SCLC tumor tissues and the majority of the SCLC cell lines (17). Src is a major upstream regulator of Stat3 (31), and activated Src-TK can phosphorylate Stat3(Y705) $(31,32)$; in addition, the durable activation of Src-TK in tumor cells leads to a constitutive activation of Stat $3(14,24)$. To the best of our knowledge, the present findings are the first to demonstrate that treatment with LG-EO or citral reduces the phosphorylation of Stat3(Y705) and Src(Y416) in all the SCLC cell lines examined. These findings suggest that LG-EO and citral both inhibit the constitutive activation of Src-TK, resulting in reduction of the constitutive phosphorylation of Stat3(Y705).

To confirm the correlation between the upregulation of Src-TK and Stat 3 activation, wt-src-transfected and Src-overexpressing LU135-wt-src cells were constructed and treated with LG-EO or citral. The level of the phosphorylation of Stat3(Y705) in the LU135-wt-src cells was clearly higher compared with that in the control LU135-mock cells, in correlation with the amounts of Src protein and activated p-Src(Y416). Treatment with each of the reagents reduced the activated p-Stat3(Y705) in both transfectants, but the reduction in the LU135-wt-src cells was attenuated compared with that in the control LU135-mock cells. As expected, therefore, the inhibitory effect of each reagent on the proliferation/survival of the LU135-wt-src cells was significantly attenuated compared with that in the LU135-mock cells. Consistent with these findings, Src overexpression and upregulated Stat3(Y705) phosphorylation clearly inhibited the LG-EO- or citral-induced apoptosis of LU135-wt-src cells.

To verify the results using LG-EO or citral, the transfectants were treated with the Src-TK inhibitor PP2. PP2 preferentially inhibits Src family TKs, without inhibiting other TKs $(33,34)$. Treatment with PP2 almost completely inhibited the phosphorylation of $\operatorname{Src}(Y 416)$ in both transfectants, whereas the activated $\mathrm{p}$-Stat3(Y705) remained more detectable in the LU135-wt-src compared with the LU135-mock cells. These findings indicate that there are TKs other than Src-TK, which are resistant to PP2 and able to phosphorylate Stat3(Y705), and/or that LG-EO or citral may directly suppress the phosphorylation of Stat3(Y705).

Despite a favorable response to initial chemotherapy, SCLC almost invariably relapses, and relapsed tumors are generally refractory to chemotherapy. The oncogenic Stat3 signaling pathway is associated not only with cell transformation, but also with intrinsic drug resistance $(15,35)$. Stat 3 activation has been shown to confer a drug-resistant phenotype on cancer cells, upregulating the expression of anti-apoptotic factors, such as Bcl-xL and Mcl-1, in the cells, whereas downregulation of Stat3 activation reduced drug resistance (36). In the present study, the resistance to the four conventional chemotherapeutic agents was compared between the Src-overexpressing LU135-wt-src and the control LU135-mock cells. The LU135-wt-src cells were significantly more resistant to all chemotherapeutic agents compared with the control cells. Consistently with previous reports $(15,35)$, Stat 3 activity constitutively upregulated by Src overexpression enhanced the resistance to chemotherapeutic agents in the LU135-wt-src cells.

The activation of Akt is also known to promote the resistance of cancer cells to chemotherapeutic agents $(37,38)$. The suppression of Akt has been reported to enhance the cytotoxicity of anticancer drugs, such as doxorubicin $(39,40)$ and AMR (21). Activation of Src-TK leads to Akt stimulation (41). Selective Src inhibitors were shown to effectively suppress Akt activity in parallel with Src-TK inhibition (21). In the present study, constitutively activated p-Akt(S473) was clearly detected in the LU134AM and LU165 SCLC cell lines, but not in LU135, MN1112 or LU135-wt-src cells (data not shown). However, the MN1112 cells were significantly more resistant to each of the four chemotherapeutic agents compared with the LU134AM cells, in which activated p-Akt(S473) was clearly detected. These findings suggest that $\mathrm{Src} / \mathrm{Stat} 3$ activation also confers resistance to chemotherapeutic agents on SCLC cells in which activated p-Akt(S473) was not detected.

Finally, the combination effect of citral and each conventional chemotherapeutic agent on the relatively chemoresistant SCLC cell lines LU135-wt-src, LU165 and MN1112 was evaluated. Treatment with the combination of citral and each of the anticancer drugs CDDP, VP-16, AMR and SN38 at concentrations of $\mathrm{IC}_{50}$ or less appeared to exhibit at least additive or more potent combination effects on the proliferation/survival of all of the chemoresistant cell lines examined. The CI value of MN1112 cells for the combination treatment of citral with CDDP or SN38 was very close to 1 , which indicates an additive effect.

Phase II trials of the Src-TK inhibitors dasatinib (42) and saracatinib (43) were conducted for patients with chemosensitive relapsed and advanced-stage SCLC, respectively. In both trials, the specific efficacy criteria in the clinical setting were not met. It was reported that dasatinib only exerted a weak inhibitory effect on the proliferation/survival of the lung adenocarcinoma cell line A549, and did not inhibit the phosphorylation of Stat3(Y705) in these cells (44). Saracatinib also exerted little effect on tumor growth in preclinical models (43).

By contrast, LG-EO and citral both inhibited the phosphorylation of Stat3(Y705) and suppressed the proliferation/survival of A549 cells (unpublished data), as well as of the SCLC cell lines examined in the present study. The results 
from our present experiments suggest that the mechanism by which LG-EO and citral inhibit Src-TK activity may be distinguished from the mechanism of Src-TK inhibition by either of the two inhibitors dasatinib and saracatinib. Taken together, our findings suggest that either LG-EO or citral, alone or in combination with chemotherapeutic agents, may represent a novel therapeutic option for patients with SCLC.

\section{Acknowledgements}

The authors would like to thank Ms. Suzuka Kijitori-Ohta for her excellent technical assistance, and Mr. Bruce Davis of KN International for his editing of this manuscript.

\section{Funding}

No funding was received.

\section{Availability of data and materials}

The analyzed data sets generated during the study are available from the corresponding author on reasonable request.

\section{Authors' contributions}

TM and TT conceived and designed the experiments, and wrote the manuscript. TM, TT, YK, AK and GY performed the experiments. TM, TT and TK analysed the data. OI, HD, SB and NK participated in the design of the study and helped perform the analysis with constructive discussions. All authors read and approved the final manuscript.

\section{Ethics approval and consent to participate}

Not applicable.

\section{Consent for publication}

Not applicable.

\section{Competing interests}

The authors declare that they have no competing interests.

\section{References}

1. van Meerbeeck JP, Fennell DA and De Ruysscher DK: Small-cell lung cancer. Lancet 378: 1741-1755, 2011.

2. William WN Jr and Glisson BS: Novel strategies for the treatment of small-cell lung carcinoma. Nat Rev Clin Oncol 8 : 611-619, 2011.

3. Kim YH and Mishima M: Second-line chemotherapy for smallcell lung cancer (SCLC). Cancer Treat Rev 37: 143-150, 2011.

4. Carbajal D, Casaco A, Arruzazabala L, Gonzalez R and Tolon Z: Pharmacological study of Cymbopogon citratus leaves. J Ethnopharmacol 25: 103-107, 1989.

5. Figueirinha A, Cruz MT, Francisco V, Lopes MC and Batista MT: Anti-inflammatory activity of Cymbopogon citratus leaf infusion in lipopolysaccharide-stimulated dendritic cells: Contribution of the polyphenols. J Med Food 13: 681-690, 2010.

6. Francisco V, Figueirinha A, Neves BM, García-Rodríguez C, Lopes MC, Cruz MT and Batista MT: Cymbopogon citratus as source of new and safe anti-inflammatory drugs: Bio-guided assay using lipopolysaccharide-stimulated macrophages. J Ethnopharmacol 133: 818-827, 2011.
7. Onawunmi GO, Yisak WA and Ogunlana EO: Antibacterial constituents in the essential oil of Cymbopogon citratus (DC.) Stapf. J Ethnopharmacol 12: 279-286, 1984.

8. Wannissorn B, Jarikasen S and Soontorntanasart T: Antifungal activity of lemongrass oil and lemongrass oil cream. Phytother Res 10: 551-554, 1996.

9. Pattnaik S, Subramanyam VR, Bapaji M and Kole CR: Antibacterial and antifungal activity of aromatic constituents of essential oils. Microbios 89: 39-46, 1997.

10. Manosroi J, Dhumtanom P and Manosroi A: Anti-proliferative activity of essential oil extracted from Thai medicinal plants on KB and P388 cell lines. Cancer Lett 235: 114-120, 2006.

11. Boyland E and Mawson EH: Experiments on the chemotherapy of cancer: The effect of aldehydes and glucosides. Biochem J 32: 1982-1987, 1938.

12. Chaouki W, Leger DY,Liagre B, Beneytout JL and Hmamouchi M: Citral inhibits cell proliferation and induces apoptosis and cell cycle arrest in MCF-7 cells. Fundam Clin Pharmacol 23: 549-556, 2009.

13. Dudai N, Weinstein Y, Krup M, Rabinski T and Ofir R: Citral is a new inducer of caspase-3 in tumor cell lines. Planta Med 71: 484-488, 2005.

14. Bromberg JF, Wrzeszczynska MH, Devgan G, Zhao Y, Pestell RG, Albanese C and Darnell JE Jr: Stat3 as an oncogene. Cell 98: 295-303, 1999.

15. Barré B, Vigneron A, Perkins N, Roninson IB, Gamelin E and Coqueret O: The STAT3 oncogene as a predictive marker of drug resistance. Trends Mol Med 13: 4-11, 2007.

16. Ikuta K, Takemura K, Kihara M, Nishimura M, Ueda N, Naito S, Lee E, Shimizu E and Yamauchi A: Overexpression of constitutive signal transducer and activator of transcription 3 mRNA in cisplatin-resistant human non-small cell lung cancer cells. Oncol Rep 13: 217-222, 2005.

17. Pfeiffer M, Hartmann TN, Leick M, Catusse J, Schmitt-Graeff A and Burger M: Alternative implication of CXCR4 in JAK2/STAT3 activation in small cell lung cancer. Br J Cancer 100: 1949-1956, 2009.

18. Rosen N, Bolen JB, Schwartz AM, Cohen P, DeSeau V and Israel MA: Analysis of pp60 $60^{\mathrm{c}-\mathrm{src}}$ protein kinase activity in human tumor cell lines and tissues. J Biol Chem 261: 13754-13759, 1986.

19. Mazurenko NN, Kogan EA, Zborovskaya IB and Kisseljov FL: Expression of pp60 ${ }^{\text {c-src }}$ in human small cell and non-small cell lung carcinomas. Eur J Cancer 28: 372-377, 1992.

20. Mellström K, Bjelfman C, Hammerling U and Påhlman S: Expression of c-src in cultured human neuroblastoma and small-cell lung carcinoma cell lines correlates with neurocrine differentiation. Mol Cell Biol 7: 4178-4184, 1987.

21. Ueda Y, Igishi T, Hashimoto K, Suyama H, Araki K, Sumikawa T, Takeda K, Nakazaki H, Matsunami K, Kodani M, et al: Synergistic cell growth inhibition by the combination of amrubicin and Akt-suppressing tyrosine kinase inhibitors in small cell lung cancer cells: Implication of c-Src and its inhibitor. Int J Oncol 34: 689-696, 2009.

22. Roelle S, Grosse R, Buech T, Chubanov V and Gudermann T: Essential role of Pyk2 and Src kinase activation in neuropeptideinduced proliferation of small cell lung cancer cells. Oncogene 27: 1737-1748, 2008.

23. Harada D, Takigawa N and Kiura K: The role of STAT3 in non-small cell lung cancer. Cancers (Basel) 6: 708-722, 2014.

24. Bowman T, Garcia R, Turkson J and Jove R: STATs in oncogenesis. Oncogene 19: 2474-2488, 2000.

25. Song L, Turkson J, Karras JG, Jove R and Haura EB: Activation of Stat 3 by receptor tyrosine kinases and cytokines regulates survival in human non-small cell carcinoma cells. Oncogene 22: 4150-4165, 2003

26. Frank DA: STAT3 as a central mediator of neoplastic cellular transformation. Cancer Lett 251: 199-210, 2007.

27. Yamaji Y, Matsubara S, Yamadori I, Sato M, Fujita T, Fujita J and Takahara J: Characterization of a small-cell-lung-carcinoma cell line from a patient with cancer-associated retinopathy. Int J Cancer 65: 671-676, 1996.

28. Ichihara N, Kubota Y, Kitanaka A, Tanaka T and Taminato T: Inhibition of Src reduces gemcitabine-induced cytotoxicity in human pancreatic cancer cell lines. Cancer Lett 260: 155-162, 2008.

29. Bliss CI: The toxicity of poisons applied jointly. Ann Appl Biol 26: 585-615, 1939.

30. Foucquier $\mathbf{J}$ and Guedj M: Analysis of drug combinations: Current methodological landscape. Pharmacol Res Perspect 3: e00149, 2015. 
31. Bretz NP, Salnikov AV, Perne C, Keller S, Wang X, Mierke CT, Fogel M, Erbe-Hofmann N, Schlange T, Moldenhauer G, et al: CD24 controls Src/STAT3 activity in human tumors. Cell Mol Life Sci 69: 3863-3879, 2012.

32. Turkson J, Bowman T, Garcia R, Caldenhoven E, De Groot RP and Jove R: Stat 3 activation by $\mathrm{Src}$ induces specific gene regulation and is required for cell transformation. Mol Cell Biol 18: 2545-2552, 1998.

33. Okutani Y,Kitanaka A, Tanaka T, KamanoH,Ohnishi H, Kubota Y, Ishida T and Takahara J: Src directly tyrosine-phosphorylates STAT5 on its activation site and is involved in erythropoietininduced signaling pathway. Oncogene 20: 6643-6650, 2001.

34. Hanke JH, Gardner JP, Dow RL, Changelian PS, Brissette WH, Weringer EJ, Pollok BA and Connelly PA: Discovery of a novel, potent, and Src family-selective tyrosine kinase inhibitor. Study of Lck- and FynT-dependent T cell activation. J Biol Chem 271: 695-701, 1996.

35. Alas S and Bonavida B: Inhibition of constitutive STAT3 activity sensitizes resistant non-Hodgkin's lymphoma and multiple myeloma to chemotherapeutic drug-mediated apoptosis. Clin Cancer Res 9: 316-326, 2003.

36. Duan Z, Foster R, Bell DA, Mahoney J, Wolak K, Vaidya A, Hampel C, Lee H and Seiden MV: Signal transducers and activators of transcription 3 pathway activation in drug-resistant ovarian cancer. Clin Cancer Res 12: 5055-5063, 2006.

37. Kim D, Cheng GZ, Lindsley CW, Yang H and Cheng JQ: Targeting the phosphatidylinositol-3 kinase/Akt pathway for the treatment of cancer. Curr Opin Investig Drugs 6: 1250-1258, 2005.

38. Brognard J, Clark AS, Ni Y and Dennis PA: Akt/protein kinase B is constitutively active in non-small cell lung cancer cells and promotes cellular survival and resistance to chemotherapy and radiation. Cancer Res 61: 3986-3997, 2001.
39. Fujiwara Y, Kawada K, Takano D, Tanimura S, Ozaki K and Kohno M: Inhibition of the PI3 kinase/Akt pathway enhances doxorubicin-induced apoptotic cell death in tumor cells in a p53-dependent manner. Biochem Biophys Res Commun 340: 560-566, 2006

40. Yu HG, Ai YW, Yu LL, Zhou XD, Liu J, Li JH, Xu XM, Liu S, Chen J, Liu F, et al: Phosphoinositide 3-kinase/Akt pathway plays an important role in chemoresistance of gastric cancer cells against etoposide and doxorubicin induced cell death. Int J Cancer 122: 433-443, 2008.

41. Arcaro A, Aubert M, Espinosa del Hierro ME, Khanzada UK, Angelidou S, Tetley TD, Bittermann AG, Frame MC and Seckl MJ: Critical role for lipid raft-associated Src kinases in activation of PI3K-Akt signalling. Cell Signal 19: 1081-1092, 2007.

42. Miller AA, Pang H, Hodgson L, Ramnath N, Otterson GA, Kelley MJ, Kratzke RA and Vokes EE; Cancer and Leukemia Group B (CALGB): A phase II study of dasatinib in patients with chemosensitive relapsed small cell lung cancer (Cancer and Leukemia Group B 30602). J Thorac Oncol 5: 380-384, 2010.

43. Molina JR, Foster NR, Reungwetwattana T, Nelson GD, Grainger AV, Steen PD, Stella PJ, Marks R, Wright J and Adjei AA: A phase II trial of the Src-kinase inhibitor saracatinib after four cycles of chemotherapy for patients with extensive stage small cell lung cancer: NCCTG trial N-0621. Lung Cancer 85: 245-250, 2014

44. Song L, Morris M, Bagui T, Lee FY, Jove R and Haura EB: Dasatinib (BMS-354825) selectively induces apoptosis in lung cancer cells dependent on epidermal growth factor receptor signaling for survival. Cancer Res 66: 5542-5548, 2006. 